\title{
TRANSMISSIBILIDADE CAUSA MORTIS DA OBRIGAÇÃO ALIMENTAR
}

\section{Caroline Pomjé ${ }^{1}$}

Resumo: O presente estudo pretende analisar criticamente a (in)transmissibilidade da obrigação alimentar, a partir do método hipotético-dedutivo e com base em revisão bibliográfica. Por meio da verificação de aspectos objetivos, subjetivos e da fundamentação em torno da intransmissibilidade da obrigação alimentar, é possível identificar a necessidade de preenchimento de determinados critérios para que se proceda à transmissão.

Palavras-chave: Alimentos. Obrigação alimentar. Dívida alimentar. Transmissibilidade. Sucessores.

\section{CAUSA MORTIS TRANSMISSIBILITY OF THE SUPPORT OBLIGATION}

\begin{abstract}
The present study intends to analyze critically the (non)transmissibility of the support obligation, from the hypothetical-deductive method and based on bibliographic review. Through verification of objective and subjective aspects, and the rationale for the nontransferability of support obligation, it is possible to identify the need to fulfill certain criteria for the transfer.
\end{abstract}

Keywords: Alimony. Support obligation. Alimony debt. Transmissibility. Successors.

\section{INTRODUÇÃO}

Com fundamento no princípio da dignidade da pessoa humana, constante no art. $1^{\circ}$, da Constituição da República Federativa do Brasil de 1988, aliado ao direito à vida e ao princípio da solidariedade, o direito a alimentos encontra-se expressamente previsto no ordenamento jurídico nacional e amplamente desenvolvido doutrinariamente em termos de caracterização. Dentre suas peculiaridades, uma restará avaliada com maior profundidade no âmbito do presente artigo: a suposta intransmissibilidade da obrigação alimentar.

O estudo ora apresentado, neste contexto, buscará analisar a característica da transmissibilidade - ou não - da obrigação alimentar em caso de falecimento do devedor de

\footnotetext{
${ }^{1}$ Mestranda em Direito Privado na Universidade Federal do Rio Grande do Sul, com ênfase em Direito de Família e Sucessões. Advogada em Porto Alegre/RS. E-mail: caroline@ scarparo.adv.br.
} 
alimentos, tendo como principal problema de pesquisa o seguinte: a obrigação alimentar é transmissível ao seu espólio?

Para tanto, a questão será abordada a partir do método hipotético-dedutivo: com fundamento na elaboração de conjecturas, buscar-se-á o falseamento destas a partir da doutrina e da jurisprudência, visando, por fim, à comprovação das hipóteses, o que conduzirá às conclusões do estudo ora apresentado (FINCATO, 2014, p. 44-45). Como já mencionado, este trabalho pretende problematizar a possibilidade de transmissão da obrigação alimentar ao espólio do devedor de alimentos, fulcro no art. 1.700, do Código Civil de 2002, traçando-se como conjecturas iniciais (a) sua harmonização com o direito à herança, previsto no art. $5^{\circ}$, inciso XXX, da CRFB/1988; e (b) sua compatibilização com o princípio da igualdade entre os herdeiros, constante no art. 227, $\S 6^{\circ}$, da CRFB/1988. Para possibilitar o estudo proposto, partir-se-á de pesquisa bibliográfica aliada à análise de decisões jurisprudenciais, com enfoques em julgados do Tribunal de Justiça do Estado do Rio Grande do Sul.

No que tange às hipóteses de trabalho, estas podem ser da seguinte maneira enunciadas: a obrigação alimentar, com fundamento no art. 1.700, do Código Civil de 2002, é transmissível ao espólio do de cujus alimentante, desde que (a) o patrimônio do falecido contenha bens que produzam frutos; (b) o credor de alimentos não seja, concomitantemente, herdeiro do de cujus; e (c) em sendo herdeiro, mediante compensação junto ao seu quinhão quando da partilha de bens.

Com a finalidade de possibilitar a análise pretendida, inicialmente serão estudadas as características da obrigação alimentar, seguida da análise detida sobre a (in)transmissibilidade da obrigação, com fundamento no texto legal aplicável, do entendimento doutrinário e de decisões jurisprudenciais a respeito. Por fim, será realizada análise crítica dos diferentes entendimentos, buscando harmonizar a produção existente com o princípio constitucional da igualdade entre os herdeiros.

\section{ORIGEM DA DISCUSSÃO}

Como bem apontam Cristiano Chaves de Farias e Nelson Rosenvald, os "alimentos podem ser conceituados como tudo o que se afigurar necessário para a manutenção de uma pessoa humana, compreendidos os mais diferentes valores necessários para uma vida digna" (FARIAS; ROSENVALD, 2018, p. 728). O conceito abrange, consequentemente, não 
somente as despesas ordinárias - correspondentes a gastos com alimentação, educação, saúde e vestuário, por exemplo -, mas também as extraordinárias, que escapam à provisão de despesas básicas. Desta maneira, “a palavra 'alimentos' vem a significar tudo o que é necessário para satisfazer aos reclamos da vida" (CAHALI, 2013, p. 15), representando "uma das principais efetivações do princípio da solidariedade nas relações sociais" (TARTUCE, 2016, p. 429).

Apesar de a doutrina seguir linhas de entendimento muito semelhantes quanto às características da obrigação alimentar - dentre as quais se destacam, desde logo, o caráter personalíssimo da obrigação de alimentos, sua irrenunciabilidade, atualidade, imprescritibilidade, irrepetibilidade, incompensabilidade e impenhorabilidade - pairam discussões relevantes sobre a teórica intransmissibilidade da obrigação alimentar. Isso porque o Código Civil de 1916 previa expressamente, no seu art. 402, que "a obrigação de prestar alimentos não se transmite aos herdeiros do devedor". Consequentemente, o falecimento do devedor de alimentos ensejava a extinção da obrigação alimentar, havendo apenas a necessidade de que os herdeiros do de cujus procedessem ao pagamento dos valores eventualmente em atraso, dentro das forças da herança e de cada quinhão (FIGUEIREDO, 2012, p. 76). Assim, “considerava-se que tanto o direito de alimentos como a obrigação alimentar, sendo intransmissíveis, se extinguem com a morte do alimentário ou do alimentante" (CAHALI, 2013, p. 51). Não havia maiores divergências, portanto, dada a clareza da legislação quanto à então intransmissibilidade da obrigação alimentar.

Com o advento da Lei do Divórcio (Lei n. 6.515/1977), entretanto, houve inovação no tema: diversamente do que até então previa o art. 402, do Código Civil de 1916, o art. 23, da Lei 6.515/77, passou a afirmar que "a obrigação de prestar alimentos transmite-se aos herdeiros do devedor, na forma do art. 1.796 do Código Civil”. Destaca-se, desde logo, que o art. 1.796, do Código Civil de 1916, referido pelo art. 23, da Lei 6.515/77, dispunha que "a herança responde pelo pagamento das dívidas do falecido; mas, feita a partilha, só respondem os herdeiros, cada qual em proporção da parte, que na herança lhe coube". Redação esta reproduzida no atual art. 1.997, do Código Civil de 2002.

Ocorre que parcela da doutrina sustentava que o princípio da intransmissibilidade da obrigação alimentar (previsto, como referido anteriormente, no art. 402, do Código Civil de 1916) teria sido integralmente preservado em nosso ordenamento, "de tal modo que o art. 23 da Lei do Divórcio nada teria de inovador, tendo cuidado apenas de explicitar a responsabilidade dos herdeiros pelas prestações atrasadas, nos limites do art. 1.796 do 
CC/1916" (CAHALI, 2013, p. 61). Sílvio Rodrigues, por sua vez, destacava que a disposição do art. 23, da Lei n. 6.515/1977, referia-se unicamente aos alimentos fixados no desquite, uma vez que "o legislador de 1977 a inseriu no capítulo sobre a dissolução da sociedade conjugal" (RODRIGUES, 1978, p. 375).

Desta maneira, ainda que a literalidade do art. 23, da Lei do Divórcio, indicasse a transmissibilidade da obrigação alimentar aos herdeiros do de cujus, o entendimento no sentido de que a obrigação em questão permanecia intransmissível era bastante contundente. Contudo, com o Código Civil de 2002, especialmente em virtude do disposto no art. 1.700, a discussão ganhou novo fôlego.

\section{3 (IN)TRANSMISSIBILIDADE DA OBRIGAÇÃO ALIMENTAR NO CÓDIGO CIVIL} DE 2002

Com o advento do Código Civil de 2002, as dúvidas existentes em torno da transmissibilidade ou não da obrigação alimentar foram inflamadas. As discussões passaram a decorrer do fato de que o art. 1.700 do diploma civil dispõe textualmente que "a obrigação de prestar alimentos transmite-se aos herdeiros do devedor, na forma do art. 1.694", ensejando posicionamentos variados por parte dos doutrinadores civilistas.

Inicialmente, uma diferenciação deve ser destacada. Os alimentos post mortem podem ser devidos em favor de ex-cônjuge/ex-companheiro em decorrência do casamento/união estável ou em favor de parentes consanguíneos. Enquanto os alimentos previstos reciprocamente em favor dos cônjuges e companheiros encontram-se previstos no art. 1.694, do CCB/2002 (decorrendo da solidariedade familiar), os alimentos em favor de parentes consanguíneos encontram-se disciplinados nos arts. 229, da CRFB/88, e no art. 1.696, do CCB/2002 (decorrendo, no caso de alimentos devidos a filhos, do poder familiar).

De qualquer maneira, razoável destacar que só se pode pretender a transmissão da obrigação alimentar caso o falecido tenha deixado patrimônio para tanto. Tal interpretação, desde logo salientada, fundamenta-se nas considerações trazidas, ainda na década de 1970, por Sérgio Gischkow Pereira. Para referido autor, a possibilidade de pura e simples transmissão da obrigação alimentar aos herdeiros do alimentante, mesmo nos casos de inexistência de subsídios patrimoniais para tanto, ensejaria situações absolutamente injustas: 
Assentado fica, parece-me pacífico e incontroverso, não pode prevalecer a primeira solução, com a transmissão pura e simples do encargo alimentar, sem que o seja em função das forças da herança; seria uma violência jurídica inqualificável; podem ser colhidos outros exemplos de situações intoleráveis: a) A casa com B e não têm filhos; divorciam-se; A, do sexo masculino, volta a casar-se, desta vez com C, surgindo filhos; falece A, com o que seus filhos com $\mathrm{C}$ ficam obrigados a suportar a pensão para com $\mathrm{B}$ ainda que nada herdassem [...]. (PEREIRA, 1979, p. 27).

Consequentemente, poder-se-ia cogitar da transmissibilidade da obrigação alimentar desde que o patrimônio do de cujus comportasse tal encargo, sob pena de onerar o patrimônio de terceiros com tal obrigação. Diante disso, basicamente cinco diferentes interpretações têm sido conferidas ao disposto no art. 1.700, do Código Civil:

(1) Entendimento de que somente as parcelas alimentares vencidas e não pagas até o falecimento do alimentante seriam objeto de transmissão aos seus sucessores, de modo que não ocorreria transmissão da obrigação alimentar, mas apenas do débito alimentar já devidamente constituído;

(2) Entendimento de que poderia ocorrer apenas a transmissão da obrigação alimentar para os descendentes do de cujus no caso de o credor de alimentos não ser, concomitantemente, herdeiro; nesta hipótese, o credor continuaria recebendo as prestações alimentícias, por parte do espólio, até a efetivação da partilha dos bens;

(3) Entendimento no sentido de que, em sendo o credor de alimentos concomitantemente herdeiro, não ocorreria a transmissão da obrigação alimentar;

(4) Entendimento de que, em sendo o credor de alimentos também herdeiro do de cujus, ocorreria a transmissão da obrigação alimentar ao espólio, até a perfectibilização da partilha, com a necessidade de compensar o montante recebido a título de alimentos do quinhão que caberia ao herdeiro; e

(5) Entendimento de que, em sendo o credor de alimentos também herdeiro do de cujus, ocorreria a transmissão da obrigação alimentar ao espólio, até a perfectibilização da partilha, sem a necessidade de compensar o montante recebido a título de alimentos do quinhão que caberia ao herdeiro.

Passa-se à análise pormenorizada.

Inicialmente, há aqueles que defendem que ocorre unicamente a transmissão da dívida alimentar, isto é, das prestações vencidas e não pagas até o falecimento do devedor de alimentos. Seguindo essa linha de entendimento, Paulo Lôbo destaca que "a transmissão é exclusivamente do débito constituído até o falecimento" (LÔBO, 2017, p. 367), de modo que 
não se trataria de uma exceção à regra geral da intransmissibilidade da obrigação alimentar e não seria possível "o requerimento de ação de alimentos contra espólio de alimentante, se não houver alimentos fixados em acordo ou sentença em seu favor antes do falecimento do autor da herança" (LÔBO, 2017, p. 367). No mesmo sentido, Antonio Borges de Figueiredo destaca que "a prestação de alimentos tem caráter personalíssimo e deve cessar com o óbito do alimentante ou do alimentando, ressalvada a responsabilidade do espólio pelas prestações vencidas antes da abertura da sucessão, dentro da sua força” (FIGUEIREDO, 2012, p. 82). Não há dúvidas, porém, que as parcelas devidas e não pagas pelo devedor de alimentos até o seu falecimento "representam dívida de direito comum, a ser deduzida do monte partilhável" (CAHALI, 2013, p. 79).

Entretanto, do entendimento acima indicado verifica-se desde logo o seguinte problema: a redação do art. 1.700 , do Código Civil de 2002, é clara ao afirmar que ocorre a transmissão da obrigação de prestar alimentos em caso de falecimento do devedor de alimentos. E a obrigação de prestar alimentos não se confunde com as parcelas já vencidas e não pagas pelo alimentante, as quais compõem uma dívida alimentar. Importante destacar, a esse respeito, novamente as lições de Sérgio Gischkow Pereira:

\begin{abstract}
De outra parte, entender que a lei comente alude ao débito existente no momento do falecimento do autor da herança é exegese por demais estreita e que não acompanha o evoluído pensamento legislativo no tema. A obrigação alimentar é de natureza especialíssima, é de altíssima relevância, pois dela depende a própria vida. Por que, então, sobrepor a ela simples interesses hereditários? Os bens do acervo hereditário devem primeiro responder pelo pagamento dos alimentos; depois se contentarão os herdeiros. Se o capital a ser constituído absorver toda a herança, não vejo nisto problema algum. Em regra ninguém espera uma herança para sobreviver, para ter o mínimo necessário a uma existência condigna; a herança é algo aleatório, é como que inesperado presente, doação imprevisível, questão de sorte até. Os alimentos são, a toda evidência, de características notavelmente distintas. (PEREIRA, 1979, p. 27-28).
\end{abstract}

Apesar da crítica existente em face do entendimento doutrinário pelo qual não ocorreria a transmissão da obrigação alimentar - que atualmente parece desconsiderar a literalidade do disposto no art. 1.700, do diploma civil -, fato é que o Tribunal de Justiça do Estado do Rio Grande do Sul já proferiu decisões seguindo essa linha de entendimento. Em acórdão recente, julgado em 22 de novembro de 2017, a Sétima Câmara Cível do Tribunal de Justiça do Estado do Rio Grande do Sul decidiu pelo descabimento da execução de alimentos 
além daqueles a que o falecido já estava obrigado quando do seu óbito. Isso porque a obrigação de pagar alimentos teria sido extinta a partir do óbito do devedor de alimentos:

A transmissão da obrigação alimentar de que trata a lei e a que se refere a recorrente não implica pura e simples transmissão da obrigação alimentar contraída pelo falecido, e o óbito da pessoa obrigada a prestar alimentos gera as seguintes consequências:

a) primeiro, se houver dívida, ela se transmite ao espólio, isto é, os seus bens respondem pelo adimplemento da obrigação;

b) segundo, legitima o alimentando a postular alimentos dos demais parentes elencados nos art. 1.696 a 1.698 do Código Civil;

c) terceiro, se o de cujus deixar bens capazes de produzir renda, os herdeiros do devedor ficam obrigados a prestar alimentos, nos termos do art. 1.700 do Código Civil.

Portanto, a dívida alimentar existente se transmite ao espólio, mas não a obrigação de continuar pagando os alimentos a que estava obrigado o de cujus.

Morrendo o alimentante e deixando bens que produzem renda, alimentando, se tiver necessidade, poderá promover ação de alimentos contra os herdeiros, a fim de que seja fixada pensão alimentícia em seu favor e nisso consiste a transmissão da obrigação alimentar de que trata o art. 1.700 do CCB. (Grifei). (TRIBUNAL DE JUSTIÇA DO ESTADO DO RIO GRANDE DO SUL, Agravo No 70075260174, Sétima Câmara Cível, Relator: Liselena Schifino Robles Ribeiro, Julgado em 22/11/2017).

Do acórdão acima indicado, tem-se interessante indicativo: a interpretação conferida pelos julgadores ao disposto no art. 1.700, do CC/2002, quanto à transmissão da obrigação de prestar alimentos, referia-se à possibilidade de, falecido o alimentante e deixando bens que produzissem frutos (como imóveis com os quais pudessem os sucessores perceber alugueis), o credor de alimentos poderia ajuizar uma ação de alimentos em face dos herdeiros, visando à fixação de pensão alimentícia em seu favor. Não haveria, assim, uma transmissão "automática" da obrigação de prestar alimentos, havendo a necessidade de que o interessado ajuizasse uma ação específica em face dos herdeiros (terceiros em relação à obrigação alimentar originária) e desde que existissem bens que produzissem frutos.

Aderindo a essa primeira linha, Cristiano Chaves de Farias e Nelson Rosenvald (2018, p. 735) destacam que, considerando a natureza personalíssima da obrigação de prestar alimentos, não deveria ser admitida a transmissão da obrigação em questão no caso de falecimento do devedor de alimentos:

Em uma perspectiva ontológica, o óbito de um dos sujeitos da relação (o devedor de alimentos, alimentante, ou o credor, alimentando) deveria 
importar na sua automática extinção, em face da natureza intuito personae. Somente as prestações vencidas e não pagas é que se transmitiriam aos herdeiros, dentro das forças do espólio, por se tratar de dívida do falecido, transferidas juntamente com o seu patrimônio (relações ativas e passivas), em conformidade com a regra da transmissão operada por saisine $(\mathrm{CC}$, art. 1.784). Não vemos, portanto, com bons olhos a opção do legislador civil, desprovida de sustentação teórica e atentatória à natureza personalíssima da obrigação. Não fosse suficiente, é de se encalamistrar, ainda, que a transmissão da obrigação de prestar alimentos poderá ensejar uma desconfortável situação, que é a diminuição da herança que foi transmitida para o pagamento de uma dívida não vencida, que não é devida pelo titular do patrimônio recebido. (FARIAS; ROSENVALD, 2018, p. 735-736).

Seguindo nas lições de Cristiano Chaves de Farias e Nelson Rosenvald (2018, p. 737), depreende-se que referidos autores defendem que somente ocorreria eventual "transmissão das obrigações em favor de alimentandos que não sejam herdeiros do espólio deixado pelo falecido, sob pena de violação, por via oblíqua, do princípio constitucional da igualdade entre os filhos". Assim, tem-se que o primeiro entendimento - de completa intransmissibilidade da obrigação alimentar - seria mitigado no caso de o credor de alimentos não ser, concomitantemente, herdeiro; nesta hipótese (de o credor não ser, ao mesmo tempo, herdeiro do de cujus) aquele continuaria recebendo as prestações alimentícias, por parte do espólio, até a efetivação da partilha dos bens.

Por outro lado, em se tratando de credor de alimentos que, ao mesmo tempo, é herdeiro do falecido, Cristiano Chaves de Farias e Nelson Rosenvald encampam o entendimento de que não ocorreria a transmissão da obrigação alimentar, pois a manutenção do pagamento de alimentos ao herdeiro/credor violaria a regra constitucional da igualdade substancial entre os herdeiros:

Seria o caso de um irmão que, além de herdeiro, estaria recebendo alimentos do espólio, em detrimento dos demais irmãos, que se restringiriam à qualidade de herdeiros. Assim, o art. 1.700 da Lei Civil assevera que "só pode ter aplicação se o alimentando não é, por sua vez, herdeiro do devedor da pensão", como aduz Zeno Veloso. Levando a situação a uma compreensão, considerando que o cônjuge ou companheiro tenha participação na herança do falecido (CC, arts. 1.829 e 1.790), não poderá requerer os alimentos do espólio, pois dele já terá um quinhão a título hereditário. Trata-se de entendimento que obsta um desequilíbrio nos valores recebidos por pessoas que estão, rigorosamente, na mesma situação jurídica. (FARIAS; ROSENVALD, 2018, p. 737-738). 
Por outro lado, há quem defenda a possibilidade de transmissão da obrigação alimentar e manutenção do pagamento das prestações vincendas ao credor de alimentos que é, concomitantemente, herdeiro, mediante a necessidade de abatimento do valor recebido a título alimentar. Isso porque qualquer valor recebido pelo herdeiro antes da ultimação da partilha seria considerado como antecipação da tutela jurisdicional (FARIAS; ROSENVALD, 2018, p. 738). Por fim, defendendo posicionamento diametralmente oposto, Maria Berenice Dias destaca que as parcelas recebidas pelo credor de alimentos que é, ao mesmo tempo, herdeiro do de cujus, não precisariam der compensadas do seu quinhão hereditário (DIAS, 2016, p. $561)$.

Importa salientar, entretanto, as considerações trazidas por Antonio Borges de Figueiredo no sentido de que, a depender do tamanho do monte-mor e da duração do processo de inventário, a limitação da responsabilidade dos sucessores pelo pagamento da obrigação alimentar às forças da herança ou de cada quinhão poderá ensejar a atribuição da "herança inteiramente ao credor [...] em detrimento completo até dos herdeiros necessários, contrariando a garantia constitucional do direito à herança (art. 5, $\mathrm{XXX}$, da CF)" (FIGUEIREDO, 2012, p. 81-82). Diante desse quadro, Maria Berenice Dias destaca a alegação de parte da doutrina no sentido de que a transmissibilidade do encargo alimentar "geraria desequilíbrio na divisão da herança" (DIAS, 2016, p. 561); apesar disso, defende a transmissibilidade da obrigação em questão, uma vez que não contrariaria “o caráter personalíssimo quer do direito de receber alimentos, quer do encargo de pagar alimentos" (DIAS, 2013b, p. 254). O entendimento da doutrinadora gaúcha sustenta-se na ideia de que a obrigação de prestar alimentos permaneceria pessoal e personalíssima; o mesmo, porém, não ocorreria com o dever de prestar alimentos, que seria transmitido aos sucessores do de cujus:

A "obrigação" continua pessoal e personalíssima, mas não o "dever" de prestar alimentos, que não se extingue com a morte do prestador. Em se tratando de obrigação que garante a vida, a sucessão alcança o próprio "dever" de alimentos e não só o "débito" alimentar porventura existente quando da abertura da sucessão. O alcance dessa determinação vai além da regra geral de que a herança responde pelas "dívidas" do falecido (CC 1997). Apesar de a lei falar em transmissão aos herdeiros, a obrigação ocorre relativamente ao espólio. De qualquer modo, não é a obrigação que se transfere aos herdeiros, mas o dever de cumprimento da obrigação, segundo as forças da herança. Ocorre uma sub-rogação no dever de cumprir a prestação alimentícia.

As críticas - inúmeras e contundentes - ao dispositivo legal que consagra obrigação alimentar além da morte não se sustentam, até porque há a possibilidade de ser instituído legado de alimentos (CC 1920), de renda 
vitalícia e de pensão periódica (CC 1926), com indicação da quantidade de prestações (CC 1927). Em todas essas hipóteses há imposição aos herdeiros de pagarem tais encargos, ainda que tal esgote as forças da herança e mesmo que o credor não necessite de alimentos. (DIAS, 2013b, p. 254).

Interessante destacar que, apesar das ferrenhas críticas ao entendimento defendido por Maria Berenice Dias, o Tribunal de Justiça do Estado do Rio Grande do Sul, em julho de 2009, julgou recurso de agravo de instrumento no âmbito do qual coube a menção de que não caberia interpretar o art. 1.700, do Código Civil, “como abrangendo apenas eventuais parcelas inadimplidas até a ocasião a morte do devedor de alimentos, sob pena de tornar a regra inteiramente vazia":

AGRAVO DE INSTRUMENTO. EXECUÇÃO DE ALIMENTOS.
IMPUGNAÇÃO. RESPONSABILIDADE DO ESPÓLIO.
TRANSMISSIBILIDADE DA OBRIGAÇÃO. Configurados os
pressupostos necessidade-possibilidade, é cabível a estipulação
dos alimentos, ensejando a disposição legal da transmissibilidade
da obrigação alimentar, tornada inquestionável pelo artigo 1.700 do Código
Civil. Não cabe interpretar o referido artigo de lei como abrangendo apenas
eventuais parcelas inadimplidas até a ocasião da morte do devedor
de alimentos, sob pena de tornar a regra inteiramente vazia, pelo simples
fato de que o artigo 1.997 do CC torna o Espólio responsável pelo
pagamento das dívidas do falecido, não havendo, portanto, necessidade de
que a mesma disposição constasse em local diverso. O art. 1.700 prevêe
a transmissão da obrigação, abrangendo parcelas que se vençam inclusive
após o óbito do devedor. AGRAVO DE INSTRUMENTO DESPROVIDO.
(SEGREDO DE JUSTIÇA). (Grifei). (Agravo de Instrumento No
70029006640, Sétima Câmara Cível, Tribunal de Justiça do RS, Relator:
André Luiz Planella Villarinho, Julgado em 08/07/2009).

Em julgamento realizado em julho de 2016, entretanto, a mesma Câmara Cível do Tribunal de Justiça do Estado do Rio Grande do Sul - ainda admitindo a transmissibilidade da obrigação alimentar aos herdeiros - destacou a relevância de que, na fixação da verba alimentar, fosse verificada a necessidade do requerente e a possibilidade de o patrimônio do falecido arcar com a obrigação em questão:

INVENTÁRIO. TRANSMISSÃO DA OBRIGAÇÃO ALIMENTAR AO ESPÓLIO. 1. O estabelecimento do encargo alimentar aos herdeiros tem suporte legal na transmissibilidade da obrigação alimentar prevista no art. 1.700 do $\mathrm{CCB}$ e obedece às diretrizes do art. 1.694 do CCB. 2. O exame da adequação do encargo alimentar a ser transmitido e a fixação do quantum deve observar o contraditório e a necessária fase cognitiva. 3. A fixação da verba alimentar deve ter em mira a prova da necessidade da requerente e da 
possibilidade de o patrimônio deixado pelo falecido alimentante produzir frutos suficientes para suportar a verba. Recurso provido. (Grifei). (Apelação Cível No 70069107860, Sétima Câmara Cível, Tribunal de Justiça do RS, Relator: Sérgio Fernando de Vasconcellos Chaves, Julgado em 27/07/2016).

Verifica-se, assim, a existência de diversos entendimentos - doutrinários e jurisprudenciais - acerca da transmissibilidade (ou não) do encargo alimentar ao espólio e sucessores do falecido devedor de alimentos. Logo, o questionamento acerca da melhor interpretação a ser conferida ao art. 1.700, do Código Civil, emerge com grande importância. Sua resposta, evidentemente, perpassa pela análise dos reflexos gerados por cada uma das interpretações sobre o direito sucessório decorrente do falecimento do devedor de alimentos e sobre o princípio da igualdade entre os herdeiros.

\section{INTERPRETANDO O ART. 1.700, DO CCB/2002, À LUZ DO PRINCÍPIO DA IGUALDADE ENTRE OS HERDEIROS}

$\mathrm{O}$ art. $227, \S 6^{\circ}$, da CRFB/88 expressamente prevê que "os filhos, havidos ou não da relação do casamento, ou por adoção, terão os mesmos direitos e qualificações, proibidas quaisquer designações discriminatórias relativas à filiação". De referido dispositivo extrai-se o princípio da igualdade entre os filhos e, consequentemente, entre os sucessores. Não é admitido, portanto, qualquer tratamento discriminatório - seja durante a vida do genitor, seja em ocasião do seu falecimento, com a abertura da sucessão.

O princípio da igualdade entre os filhos e entre os herdeiros na sucessão legítima, ainda, fundamenta a disciplina existente em torno do instituto da colação - que visa a, justamente, igualar os quinhões a serem recebidos por cada herdeiro:

O dever de colacionar tem fundamento no princípio da igualdade entre os filhos, extraído do texto constitucional, e da igualdade entre os herdeiros na sucessão legítima, razão pela qual lhes devem ser atribuídas quotas idênticas da metade indisponível da herança. Conforme anteriormente ressaltado, o artigo 544 do Código Civil (LGL\2002\400) estabelece que "a doação de ascendentes a descendentes, ou de um cônjuge a outro, importa adiantamento do que lhes cabe por herança". Assim, a colação possibilita que os herdeiros-descendentes (bem como o cônjuge ou companheiro supérstites, quando herdarem em concorrência com os descendentes do de cujos) que não foram favorecidos por doações do falecido sejam 
compensados, recebendo a diferença em seu quinhão da legítima, de modo a anular qualquer desproporção entre eles (VIEIRA, 2018, p. 03).

Desta forma, verifica-se desde logo que a interpretação do disposto no art. 1.700, do Código Civil de 2002, deve ser realizada com fundamento no disposto na Constituição Federal, haja vista a existência de princípios informadores do direito sucessório. Consequentemente, a interpretação ora apresentada pretende, a um só tempo, contemplar o princípio da igualdade entre os herdeiros e a transmissibilidade da obrigação alimentar prevista expressamente no Código Civil.

Primeiramente, destaca-se que parece não pairar dúvidas acerca da transmissibilidade das prestações alimentares vencidas ao espólio. Isso porque, como já referido, tratam-se de dívidas de direito comum, as quais - estando vencidas e inadimplidas - representam débitos do falecido e, como tais, devem ser arcados pelo seu espólio. Entretanto, o problema da previsão do art. 1.700, do Código Civil, como visto, não reside neste aspecto.

Reside, isso sim, na possibilidade ou não de transmissão da obrigação alimentar enquanto composta de parcelas ainda não vencidas. Neste caso, rechaça-se desde logo o posicionamento doutrinário e jurisprudencial no sentido de que não ocorreria a transmissão da obrigação alimentar ao espólio, fundamentada no caráter personalíssimo da obrigação de prestar alimentos. Isso porque tal entendimento viola frontalmente a literalidade do disposto no Código Civil. Mais do que isto: considerando o desenvolvimento legislativo (do Código Civil de 1916, passando pela Lei do Divórcio, até chegar no Código Civil vigente) pode-se depreender que se a opção do legislador brasileiro fosse pela intransmissibilidade da obrigação, aquela estaria expressamente prevista.

Com isso, restam três interpretações viáveis:

(1) Entendimento de que poderia ocorrer apenas a transmissão da obrigação alimentar para o espólio do de cujus no caso de o credor de alimentos não ser, concomitantemente, herdeiro; nesta hipótese, o credor continuaria recebendo as prestações alimentícias, por parte do espólio, até a efetivação da partilha dos bens;

(2) Em sendo o credor de alimentos também herdeiro do de cujus, ocorreria a transmissão da obrigação alimentar ao espólio, até a perfectibilização da partilha, com a necessidade de compensar o montante recebido a título de alimentos do quinhão que caberia ao herdeiro; e

(3) Entendimento de que, em sendo o credor de alimentos também herdeiro do de cujus, ocorreria a transmissão da obrigação alimentar ao espólio, até a perfectibilização da 
partilha, sem a necessidade de compensar o montante recebido a título de alimentos do quinhão que caberia ao herdeiro.

Invertendo a ordem acima exposta, tem-se que o terceiro entendimento (de acordo com o qual o credor de alimentos/herdeiro permaneceria recebendo a parcela alimentar, sem necessidade de compensar o montante recebido a título de alimentos do seu quinhão hereditário) viola o princípio da igualdade entre os sucessores. Isso porque, na prática, o credor de alimentos acabaria recebendo quinhão superior ao dos demais herdeiros. Trata-se da hipótese classicamente trazida pela doutrina como razão de rechaço à transmissibilidade da obrigação alimentar. Destaca-se, entretanto, que a característica da incompensabilidade das parcelas alimentares obviamente deve ser mitigada em face desse adiantamento, sob pena de violação, como visto, da igualdade entre os herdeiros.

Por outro lado, duas parecem ser as interpretações possíveis para o art. 1.700, do Código Civil, à luz da Constituição Federal. A primeira, considerando que o credor de alimentos não seja, ao mesmo tempo, herdeiro do de cujus; e, a segunda, considerando que o credor seja, concomitantemente, herdeiro do falecido.

$\mathrm{Na}$ primeira hipótese, em se tratando de obrigação alimentar estabelecida entre o falecido e pessoa que não é, ao mesmo tempo, sua herdeira, tem-se que o espólio permaneceria contemplando a obrigação alimentar até a efetivação da partilha. Importante reiterar, aqui, o posicionamento de acordo com o qual a obrigação alimentar só será mantida por parte do espólio caso existam bens que produzam frutos, possibilitando a continuidade das prestações. Por óbvio, o patrimônio pessoal dos sucessores não poderá ser atingido caso o patrimônio do espólio seja insuficiente à manutenção da obrigação alimentar.

$\mathrm{Na}$ segunda hipótese, em se tratando de obrigação alimentar estabelecida entre o falecido e pessoa que é, simultaneamente, sua herdeira (como um filho menor de idade advindo de outra relação afetiva), ocorrerá a transmissão da obrigação alimentar ao espólio, até a realização da partilha. Aqui, do mesmo modo, frisa-se o entendimento de acordo com o qual as prestações alimentares deverão ser mantidas a partir dos frutos decorrentes dos bens componentes do espólio.

Ainda, em sendo o credor de alimentos herdeiro, deverá ocorrer, posteriormente, a compensação dos valores recebidos a título de obrigação alimentar do seu quinhão hereditário. Obviamente, reitera-se, a característica da incompensabilidade das verbas alimentares deverá ser relativizada em prol de uma interpretação constitucional da transmissibilidade da obrigação alimentar. 
Desta maneira, será possibilitada a manutenção do credor alimentar até a ultimação da partilha, momento em que receberá o seu quinhão e terá, ao menos em tese, condições de prover sua subsistência:

Como, em regra, o credor dos alimentos é herdeiro, ao receber seu quinhão hereditário passa a prover à própria subsistência. Se para isso não é suficiente a herança percebida, surge o direito de pleitear alimentos frente aos parentes. Mas é obrigação de outra origem, tendo por fundamento a solidariedade familiar (CC 1.694) (DIAS, 2013a, p. 40).

Subsistindo a necessidade do credor após findo o processo de inventário, mediante a partilha dos bens componentes do espólio, poder-se-ia cogitar do ajuizamento de nova ação desta vez pleiteando alimentos dos herdeiros do de cujus, desde que legitimados passivos para tanto. A obrigação do falecido, neste caso, terá sido extinta, dando lugar a eventual obrigação por parte de terceiros.

A interpretação conferida ao art. 1.700, do Código Civil, portanto, dependerá da condição do credor de alimentos: se é, ao mesmo tempo, herdeiro do de cujus ou não. Por intermédio dessa interpretação, o princípio da igualdade entre os sucessores restará respeitado, possibilitando, simultaneamente, a manutenção das condições de vida do credor, haja vista a relevância da obrigação alimentar.

\section{CONCLUSÃO}

Apesar da suposta facilidade interpretativa decorrente do teor do art. 1.700, do Código Civil de 2002, restou demonstrada, por meio do presente estudo, a existência de diversos posicionamentos doutrinários e jurisprudenciais em torno de referido dispositivo. A transmissibilidade da obrigação alimentar, assim, não representa questão pacífica em nosso ordenamento jurídico, demandando esforço interpretativo para ser compatibilizada especialmente com o princípio da igualdade entre os sucessores, previsto no art. $227, \S 6^{\circ}$, $\mathrm{CRFB} / 88$.

Essa dificuldade interpretativa, entretanto, não deve ser suficiente para obstar a outorga de significado àquilo que expressamente consta no art. 1.700, do Código Civil. Desta maneira, o entendimento pela absoluta intransmissibilidade da obrigação alimentar diante do falecimento de uma das partes, fundado no caráter personalíssimo da obrigação, deve ser 
afastado. Isso porque as características da obrigação alimentar não são absolutas, devendo ser compatibilizadas entre si e em relação aos princípios constitucionais informadores do nosso sistema jurídico.

Consequentemente, o entendimento pela transmissibilidade da obrigação alimentar deve prevalecer. Entendimento este que deverá observar a situação do credor de alimentos: em se tratando de credor que não é herdeiro do de cujus, o pagamento da obrigação alimentar, por meio dos frutos decorrentes do espólio, deverá ocorrer até a realização da partilha. Por outro lado, em se tratando de credor que é concomitantemente herdeiro do falecido, o pagamento da obrigação alimentar deverá ocorrer até a realização da partilha, com a necessidade de compensação dos valores recebidos a título de alimento do quinhão hereditário a que o herdeiro em questão faz jus.

Importa destacar, por fim, a reserva no sentido de que a transmissibilidade da obrigação alimentar ocorre em relação ao espólio, assim considerado o conjunto das relações patrimoniais deixadas pelo falecido. Essa ressalva se faz importante na medida em que o art. 1.700, do CCB/2002, prevê a transmissão da obrigação alimentar aos sucessores do de cujus, hipótese que - levada às últimas consequências - não pode ser admitida na medida em que acabaria onerando patrimônio de terceiros em decorrência de obrigação que compunha a esfera jurídica do falecido. Logo, tem-se que a transmissão da obrigação alimentar ocorrerá em relação ao espólio, desde que este contenha bens que produzam frutos capazes de ensejar a manutenção do pagamento das prestações vincendas. Destaca-se, porém, que poderá o credor de alimentos - diante da persistência de sua necessidade - pleitear prestação alimentar me face de outros parentes legitimados. Estes, no entanto, não serão decorrentes do vínculo existente com o falecido, mas sim com esses novos sujeitos legitimados ao pagamento da prestação alimentar. 


\section{REFERÊNCIAS BIBLIOGRÁFICAS}

BRASIL. Constituição da República Federativa do Brasil. Disponível em: http://www.planalto.gov.br/ccivil_03/constituicao/constituicao.htm. Acesso em: 31 jul. 2018.

BRASIL. Lei 6.515, de 26 de dezembro de 1977. Disponível em: http://www.planalto.gov.br/Ccivil_03/leis/L6515.htm. Acesso em: 31 jul. 2018.

BRASIL. Lei $\mathrm{n}^{\mathrm{o}}$ 10.406, de 10 de janeiro de 2002. Código Civil. Disponível em: http://www.planalto.gov.br/ccivil_03/Leis/2002/110406.htm. Acesso em: 31 jul. 2018.

BRASIL. Lei $\mathrm{n}^{\circ} 3.071$, de $1^{\circ}$ de janeiro de 1916. Código Civil dos Estados Unidos do Brasil. Disponível em: http://www.planalto.gov.br/Ccivil_03/leis/L3071.htm. Acesso em: 31 jul. 2018.

CAHALI, Yussef Said. Dos alimentos. 8. ed. rev. e atual. São Paulo: Editora Revista dos Tribunais, 2013.

DIAS, Maria Berenice. Alimentos aos bocados. São Paulo: Editora Revista dos Tribunais, 2013.

DIAS, Maria Berenice. Manual das Sucessões. 3. ed. rev., atual. e ampl. São Paulo: Editora Revista dos Tribunais, 2013.

DIAS, Maria Berenice. Manual de Direito das Famílias. 11. ed. rev., atual. e ampl. São Paulo: Editora Revista dos Tribunais, 2016.

FARIAS, Cristiano Chaves de; ROSENVALD, Nelson. Curso de Direito Civil: Famílias. 10. ed. rev. e atual. Salvador: Ed. JusPodivm, 2018.

FIGUEIREDO, Antonio Borges de. Alimentos: a obrigação de prestá-los do espólio. Revista Magister de Direito Civil e Processual Civil, Porto Alegre, ano VIII, n. 46, p. 75-83, jan/fev. 2012.

FINCATO, Denise Pires. A pesquisa jurídica sem mistérios: do projeto de pesquisa à banca. 2. ed. rev. e ampl. Porto Alegre: Sapiens, 2014.

LÔBO, Paulo. Direito Civil: Famílias. 7. ed. São Paulo: Saraiva, 2017.

PEREIRA, Sérgio Gischkow. Ação de alimentos. Coleção AJURIS/11. Porto Alegre: Editora Síntese Ltda., 1979.

RODRIGUES, Sílvio. Direito de Família. 6. ed. São Paulo: Saraiva, 1978.

TARTUCE, Flávio. O novo CPC e o Direito Civil. Impactos, diálogos e interações. 2. ed. rev., atual. e ampl. Rio de Janeiro: Forense; São Paulo: MÉTODO, 2016. 
TRIBUNAL DE JUSTIÇA DO ESTADO DO RIO GRANDE DO SUL, Agravo de Instrumento $N^{o} 70029006640$, Sétima Câmara Cível, Relator: André Luiz Planella Villarinho, Julgado em 08/07/2009.

TRIBUNAL DE JUSTIÇA DO ESTADO DO RIO GRANDE DO SUL, Agravo $N^{o}$ 70075260174, Sétima Câmara Cível, Relator: Liselena Schifino Robles Ribeiro, Julgado em $22 / 11 / 2017$.

TRIBUNAL DE JUSTIÇA DO ESTADO DO RIO GRANDE DO SUL, Apelação Cível $N^{o}$ 70069107860, Sétima Câmara Cível, Relator: Sérgio Fernando de Vasconcellos Chaves, Julgado em 27/07/2016.

VIEIRA, Carla Eduarda de Almeida. Direito das sucessões e o novo Código de Processo Civil: considerações sobre as idas e vindas da colação. Revista de Direito Civil Contemporâneo, São Paulo, vol. 15, p. 299-317, abr-jun/2018. 